\title{
The context of presenting "others": the construction of meaning and the potential of communication in ethnographic film
}

\author{
Xun Xiong ${ }^{1} \cdot$ Jing $\mathrm{Li}^{2}$
}

Received: 4 April 2021 / Accepted: 14 April 2021 / Published online: 08 June 2021

(C) The Author(s). 2021

\begin{abstract}
How can images be used as an expressive, yet clearly limited, tool to represent "the other" in ethnographic films? Based on the objectives of visual anthropology and visual communication, this article analyzes the four presentational traditions of meaning construction. These traditions have been incorporated into the audiovisual communication context to illustrate the similarities or differences between ethnographic films and ethnographic texts in terms of traditions, structures, features, and limitations. Through the analysis of the four traditions, the relationships between visual presentation and text writing, visual patterns and communication concepts, and visual potentials and ethnographic films have been fully examined. In the context of Chinese ethnographic films, the four presentational traditions have been well showcased and developed. These works, in their different contexts, have constituted a meaningful visual text system of contemporary Chinese anthropology.
\end{abstract}

Jing Li

58432984@qq.com

Xun Xiong

xiongx6@mail.sysu.edu.cn

1 School of Communication and Design, Sun Yat-sen University, 132 Waihuan Road (E), Higher Education Mega Center, Panyu District, Guangzhou, Guangdong Province, People's Republic of China

2 Nanfang College of Sun Yat-sen University, 882 Wenquan Avenue, Wenquan Town, Conghua District, Guangzhou, Guangdong Province, People's Republic of China 
Keywords Ethnographic film - Presentational tradition - Communication context · Text and image

\section{Introduction}

Through the function of mechanical reproduction, the two inventions of photography and cinematography have fundamentally tackled the persistent problems of realism in visual representation, and released image production from its classification as a "plastic art". What distinguishes the two great inventions from others is their objective "essentialism" - between the object world and visual representations, only one other entity plays a role. The aesthetic value of static documentary photography and dynamic documentary cinematography lies in "revealing the truth" (Bazin 2008). However, as visual technologies and audio-visual presentational methods constantly evolve, people have gained an ever deeper understanding of visual communication: films have not only entered an "era lacking enlightenments", where they were reduced to marginal visual products compared with the dominant texts; but also failed to present the essence of reality, thus resulting in a crisis of trust over authenticity.

As a disciplinary product and research subject of anthropology, the development of ethnographic films dates back to the emergence of modern ethnography. Unlike ethnographies presented in the written form, ethnographic films in the narrow sense are required to have the same "documentary and theoretical values" as written ethnographies in the strictly defined field of anthropological academic production. Moreover, they are also expected to serve as a tool of mass communication, and be of "promotional value" for anthropological studies: ethnographic films are viewed as the visual appendix to the anthropological research text, in the hope of allowing the general public to have a better understanding of these topics. On the one hand, this article looks beyond ethnographic films and highlights the broader ideological trends and communication contexts showcased. On the other hand, it elaborates the relationship between the presentation context and the society-wide communication of ethnographic films, focusing on dialogues and negotiations between texts and images. I have found that ethnographic films are similar to textual ethnographies, as they are closely related to contemporary epistemological perspectives. In addition, they have established an intriguing relationship with the evolving traditions, methods, and concepts of visual communication-one which is intimate at times yet distant at others.

\section{Methods}

As the discipline constantly evolves, anthropology has been marching ever closer to the humanities, having departed from an essentialism and scientific paradigm. During its theoretical development, each newly formed theory usually embodies a tendency to reflect on the previous ones (Qu Ming'an 2009). To illustrate the communication process of both ethnographic texts and ethnographic films, I have paid 
due attention to the object filmed (or research object), the ethnographic filmmaker (or writer), and the audience (or readers). Moreover, I have classified their sociocultural contexts into three fields: the object world, the world of communicators, and the world of audience or reader. The object world means the group and society being selected, studied, and filmed. The world of communicators stands for the group and society of fieldworkers, anthropologists, and ethnographic filmmakers (often including producing, editing, publishing, and so on). The world of audience includes the obvious and potential audience of ethnographic films and the sociocultural contexts behind them. What is worth mentioning is that, the "distinctive" boundaries among the three worlds are usually unclear and interwoven.

Through the perspective of that understanding, the author has classified the existing ethnographic films, namely, the interpretation tradition, the narrative tradition, the avant-garde tradition and the reflexive tradition. In each of the following sections, the author will discuss in detail the relationship between the filmmaker and the object filmed, the characteristics of the film text, the advantages and disadvantages of visual communication, and the transformation in the anthropological cognitive paradigm behind them. In addition, different types of ethnographic films produced by Chinese anthropologists in recent years are introduced to readers.

\section{Results and discussion}

\section{Expository tradition and scientism}

The expository tradition uses a combination of real-life clips to form an explanatory, rhetoric, or argumentative overall structure. The focus is placed on sound logic, and authentic and sufficient evidence of the content being explained, rather than aesthetic value, poetic elegance, dramatic properties, or visual impacts. Moreover, it does not need to represent realistic continuity in terms of time or space, or portray entire events (Nichols, 2007). This tradition aims to achieve direct communication with the audience and emphasizes how effectively information is communicated. For static photography, this tradition can be seen in news photography, documentary photography, press photography, and picture stories which emerged after the establishment of modern photography. As for dynamic cinematography, this tradition has been widely used in the explanatory or introductory structure and forms of early-stage ethnographic films and documentaries about culture, nature, society, and education, as well as the argumentative structure of many "visualized political theories" proposed for promotional, motivational, critical, or disclosure purposes. The emergence of expository documentaries dates back to the $1820 \mathrm{~s}$. These documentaries, similarly to the book Argonauts of the Western Pacific, remain influential even to this day. Among the many channels of mass communication in use today, investigation-based news, in-depth reporting, biographic documentaries, and documentaries about social realities, science, and education have all continued to use the common practices and forms of the expository tradition. 
Expository films tend to set out clear and direct social positions and realistic objectives. Communicators (the film makers) play an essential role in the communication process of these films. They have mastered the visual technologies involved in "mechanically reproducing" a reality. They may occasionally or frequently "enter" the object world to take shots of what they see or what they would like to see. Through these films, directors are seeking to convince the audience that everything they see and experience in the films are "real events", thereby allowing the audience to directly relate the films to real life. In doing so, the audience steps into an agenda that is pre-arranged by the directors, wherein they accept the information provided, and agree on their hidden opinions. Therefore, many expository films have an authoritative voice-over, which is known as the "Voice of God"; or, they may make up for any gaps in the visual presentation using subtitles, to make room for both conclusive explanations and abstract deduction. Inevitably, visual materials are often viewed as secondary, placed in a solely supportive or cooperative role throughout the process. Nevertheless, due to their ambiguous and polysemous nature, visual materials have to be placed together with texts as attachments in order to disambiguate their meaning.

Behind the expository framework lies epistemology, which is best exemplified by the famous sentence of René Descartes - "whatever I perceive very clearly and distinctly is true." This optimistic belief from Descartes was first exhibited in modern natural science in the late seventeenth century. When it came to the late nineteenth century and early twentieth century, the objectives and methods of rational knowledge of the object world emerged in the field of humanities and social sciences, which directly gave birth to the trend of scientism in modern ethnography (Ruan Yunxing, 2007). Coincidently, Nanook of the North and Argonauts of the Western Pacific were both published in 1922. The former has been viewed as the first ever documentary film and anthropological film (although it is obviously not an ethnographic work in the strict sense); and the latter is a modern ethnography in the real sense (although its authority has been widely questioned due to the book $A$ Diary in the Strict Sense). As for the authors, the former was created by a mining engineer who broke into the world of cinematography by chance; and the latter was written by a doctor in physics who changed his major. It is fair to say that their stories serve as a perfect metaphor of how the paradigm of scientism entered center stage in the practice of presenting "the other".

From then on, ethnographic films and ethnographic texts underwent rapid development for nearly 50 years. As late as the 1970s, the paradigm of scientism still played a dominant role in the epistemology of anthropology. In ethnographic texts, daily lives are disrupted and reorganized. Isolated words are placed in the overall structure as evidence - the logic of classification stems from a hypothetical "whole". For instance, in Bronislaw Malinowski's seven monographs on the residents of the Trobriand Islands, the writer depicted every dimension of this "other's" society and culture. In the view of readers, a combination of all these aspects can help them reach that mysterious "other place" and understand the whole society and culture of "the others" that live there (Bingzhong 2006). However, later critics viewed this omniscient perspective as too self-important, and began to question our confidence in our understanding of the world of the other. 
The practice of ethnographic films employs the same concepts and methods as those mentioned above. Ethnographic film practices can be illustrated by the features of "realistic ethnography" which was proposed by Marcus and Cushman: expository films seek to present either a panoramic view of a society and culture, or a world or argument to be explained; the communicators act as the authority; the special existence of individuals gives way to generalized role models; images are used as as evidence (Yunxing 2007); certain specific matters are revisited as "typical cases" and so on. As for the differences, ethnographic films may appear underqualified due to their lack of a scientific foundation; while ethnographic movies struggle to become scientific ideas themselves, most of them function merely as just evidence or the "servants" of scientific paradigms and written logic. Typical examples of ethnographic films include the "Documentary Film Series of China's Ethnic Minorities: Society, History, and Science" produced from the 1950s to the 1970s, and films on the society and cultural heritages of ethnic minorities in China produced by the Institute of Ethnology (later renamed the Institute of Ethnology and Anthropology), Chinese Academy of Sciences in the late 1980s.

Over forty years later, a number of anthropologists returned to the sets of the above-mentioned films. They wanted to show their respect for the foundation of this discipline and all the efforts made in the early stage. Moreover, they wished to extend and carry forward the expository structure, reflecting and expanding the expository structure within the new context of presentation. For instance, through the film The Story of Manchunman Buddhist Temple (1999), Tan Leshui reflected upon and adjusted the presentational structure and ideological concepts in the film The Serf Society of Dai Ethnic Minority in Xishuangbanna, created by his father Tan Bibo 60 years ago. In the film Under the Shield of Geти Goddess Mountain (2008), Zhang Hai continued to focus on the marriage system shown in the ethnographic film of Walking Marriage of Yongning Naxi Ethnic Minority in Lijiang County (1976), while adopting a more balanced approach with multiple emic views. Moreover, he chose to deliberately highlight the filmmakers" "presence" to offset the previously celebrated "objective" stance. Chen Xueli's Four Chapters of Masan Village completed in 2008 opted to no longer emphasize the spectacular ritual ceremonies. Instead, he consciously turns the perspective of epistemology based on the theory of objective features of the previous work The Vas (1957), to the path of knowledge production based on daily-life interactionism. Since the 1990s, the Department of Visual Anthropology of the Institute of Ethnology and Anthropology, Chinese Academy of Social Sciences, has been dedicated to producing ethnographic films from a more theoretical perspective (Jingjiang 2014). Through solid fieldwork, an emphasis on classic topics of anthropology, the use of narrative film techniques, and the use of the researchers' academic voice-over as a narrative technique, the expository tradition has continued to this day as an effective interpretive voice, boasting both theoretical grounding and visual detail.

Evidently, the intrinsic mechanism of scientism contained within the expository tradition enables expressions to be made from a broad and holistic perspective; and the further development and impacts of positivism have also contributed to its legitimacy. During the production of expository films, the layout of texts, as well as the production cost and cycle, are more flexible and manageable. Hence, these 
films are usually favored by organizational and mass communication, with their underlying logic affecting the audience. However, in the process of interpreting "others", we can easily see that the communicators take on a privileged "God" role during the communication process, while the real object world and the initiative audience find themselves lost in countless film fragments.

\section{Narrative tradition and film production}

Audiences enjoy stories, which is not difficult to see in written texts, including ethnographies. Representative works include Lin Yaohua's The Gold Wing: A Family Chronicle, Huang Shumin's The Story of Lin Village, Levi-Strauss's Tristes Tropiques, as well as the latest No Fixed Abode: Ethnofiction, which uses dramatic narratives delivered through fictional characters and plots to offer readers a deeper understanding of the culture that is based in experience (Jingjiang 2015). Apart from the above-mentioned works, quasi-ethnographies can also be found in some literary works such as the "Anthropology of Ancient Culture" series, "Anthropology Notes" and novels on local history (Ting 2015). These works have all demonstrated efforts towards story-telling, and the relatively strong effects of communication.

Although such pro-story practices are not rare in written texts, another context which affects the way in which ethnographic films are presented should stem from the cinematic narrative tradition of feature films. After the magical 1920s, there seemed to be a sound set of techniques which ensured the prosperity of silent films. As Bazin puts it, "Be it plastic compositions or montage techniques, it is the film that manipulates different means of event reproduction and imposes all these on the audience." (Bazin 2008) The German school was dedicated to promoting plastic arts; later on, Soviet practitioners in the film industry began to explore the possibilities of montage. By 1938, the relationship between space, characters, and shots had been fully explored through practice, and the counterpoint relationship between camera movement and plot structure had been gradually standardized. As of now, the "classic mode" for narrative films is still the popular "story-telling" type, constituting an important structural paradigm dominating the film industry (Giannetti 2007).

As an operating procedure, classic narratives originate from the practice of drama, in which the motivation of the characters/actions meets with an opposing resistance to form a conflict, thus establishing a conflict arc running through a conflict structure. A typical film can adopt simple single-thread narratives or a number of seemingly complex narratives: such as multi-thread narratives in a parallel or intertwined structure, in a back-and-forth or flashback time order, or even more complex, in a nesting or circulating order. No matter how complex these narratives are, they can always be split into simple, individual narrative units. Generally speaking, writing narrative scripts has become a standardized process (especially in some giant industry chains such as Hollywood). The time-space settings and conflict arcs are similarly fixed, and visual elements such as colors, lines, spaces, movements, and tones are used to strengthen this fixed structure. In other words, this rule of standardization has nothing to do with the "art". Through industrialized, 
large-scale, and globalized film production, it has gradually evolved into a medium agenda powerful enough to guide, change, and control the world of the audience.

Ethnographies have to imagine the society and culture as a whole, and convey the "overall imagination" to the readers through descriptions of the places seen, the dialogues heard, and the people met by the authors. Similarly, in narrative films, the world in disorder has to be viewed as a narrative clue of causality or potential causality. To this end, shots should be selected and reorganized accordingly. In fact, the narrative structure is a highly simplified form of holistic imagination (which is more suitable for cross-cultural visual communication). The more integrated the narratives are, the greater the "resonance" will be between individual audio-visual elements (and between the audio-visual elements and the narrative structure), and the better the effects will be in terms of mass communication (Bingzhong 2006).

Through the globally popular media of visual communication, such as television and films, the method of arranging visual elements according to the narrative structure and the dramatic nature has formed a line of fire of repressive "magic bullets," which not only conveys the information relating to the story, but has also facilitated the stylization of film narratives and subtly formed a universal language system. This method has affected the culture of viewing and visual cognition among the global audience in a comprehensive and profound way, similar to the impacts of language on culture. Certainly, this has also left a potential impact on anthropologists and ethnographic filmmakers, no matter whether they are aware of the pressure imposed by this method, or whether they plan to resist it. Similar to ethnographic films that have been influenced by "scientific ethnography" in the case of ethnographic films which inherit the narrative tradition, when the filmmakers "observe" the object world, what they have seen is mostly a world in conflict. When they do the "field study", what they have investigated is actually the drama and potential drama occurring in the field. When they discuss the "field objects", what they are actually referring to are individual "characters". Thus there is a structured language affecting our perceptions of the object world.

In the era of mechanical reproduction, the practices of commercial films and demands of mass communication have generated a classic presentation paradigm which is comparatively "conservative" in terms of structure, and an increasing audience culture favoring "visual impact". How to effectively combine the academic objectives of anthropology and the advantages of narrative films, and how to expand the dimensions of film presentation, these two questions remain an ongoing problem in the field of visual anthropology. The above-mentioned method emphasizes conflict and prioritizes plot. Even if professional communicators are not answerable to the curse of television ratings, the "condensed narratives", "stimulated life", or "rehabilitated life" they adopt to satisfy the demands of plot development are merely the inborn restrictions of the classic paradigm itself. These restrictions work to diminish the profoundness and openness that all ethnographic films aim for, as well as the complexity and abundance of content which are necessary for the audience to understand the culture - this is what Tim Asch mocks in his ethnographic film The Ax Fight. 
However, the expressive ability of this set of film languages not only hits the audience deep in their hearts, it has also become the Achilles' heel of anthropologists who are used to written text. At the screening rooms of ethnographic films, I have observed that some films were intolerable even for professional anthropologists, perhaps because their audio-visual presentations failed to pass even the lowest acceptable standard for the audience. In addition, with their incredibly powerful in-situ descriptions, well-developed narrative films can serve as a useful tool for cross-cultural communication - they can convey the information directly, and employ rhetoric devices such as metaphor and symbolism. At the same time, the inborn drama, uncertainty, and complexity of cultural events have all amplified the strengths of narrative films.

The American direct cinema genre, represented by Robert L. Drew and Frederick Wiseman, originated in the mid twentieth century. After the genre entered the world of ethnographic film, many researchers classified these works into a separate category, namely observational documentaries. These documentaries seem to contain less intense dramatic conflicts. However, the film-based narratives and the pursuit of potential dramatic conflicts in daily lives, remain the prominent features and objectives of such documentaries. Direct-cinema documentaries are quite similar to ethnographic films - both of which feature long working hours, philosophies around non-interference with the object world, the establishment of stable and close relationships, and keeping the film as open as possible. This genre has had a farreaching impact on many Chinese professionals in the documentary filmmaking industry, who distance themselves from expository films. When it came to the turn of the twenty-first century, observational documentaries were widely favored by Chinese filmmakers and Wiseman also became a role model for them. The documentary No. 16, Barkhor South Street (1995) by Duan Jinchuan, a director who was not an anthropologist, won the Cinéma du Réel Award. Duan recorded the trivial but extremely rich administrative tasks conducted by the office of the Barkhor Neighborhood Committee in Tibet. In this documentary, all the mysterious symbols of the Tibetan culture were nowhere to be found; instead, dramatic events and cultural metaphors with ethnographic significance were found within the everyday occurrences at the office. Furthermore, many documentary filmmakers decide to adopt immersive, long-term shooting methods in order to present the dramatic stories, details, and metaphors in the constantly evolving social space. The observational perspective, focusing on society and humanism, has made these works more meaningful in terms of their anthropological value.

Anthropologist filmmakers have found that the structure of ritual, a core element of ethnographies, is basically identical to the structure of a classic drama or narrative film. Though it is a rare occasion to witness rituals that fully conform to the classic mode, ethnographers who are skilled in using structures can still easily construct the intrinsic narrative and symbolic clues needed to comply with the classic mode (Henley 2013). Hence, leveraging and probing into this isomorphic relationship between narrative and ethnographic film can help us explore more possibilities and enhance the communicative capacity of ethnographic film. In recent years, many Chinese scholars specializing in visual anthropology have adopted a discipline-centered approach and produced substantial ethnographic films through 
the methods and techniques of both narrative films and observational documentaries. For instance, over the past decade, Pang Tao, Lei Liangzhong, and others from the Institute of Ethnology and Anthropology, Chinese Academy of Social Sciences have completed holistic cultural descriptions of Deng people, Monpa people, and Lhoba people, and Sherpa people from the Luoyu Region of Tibet. Luo Hongguang, Wu Qiao, and others from the Research Center for Socio-Cultural Anthropology, Chinese Academy of Social Sciences have spent many years studying nursing homes and the culture of Huayao Dai people in Yunnan Province. These researchers have produced several documentaries in this regard, aiming to amplify the magnificent cultural heritage through in-depth descriptions of some trivial events. In 2010, the Center for Ethnic and Folk Literature and Art Development, Ministry of Culture and Tourism of the People's Republic of China, launched several large-scale audio-visual documentation projects specially commissioned by the National Social Science Fund of China, such as the Chinese Festival Video Record Project, the Chinese Epic Video Record Project, and the Record on Tradition Bearers of National Intangible Cultural Heritages.

During this period, a large number of excellent anthropological films have been produced. Among them, works of Liu Xiangchen, Zhu Jingjiang, Gui Shuzhong, Wang Ningtong, and Liu Guangyu, Wang Ningtong, Wu Xiaoqun and Chen Jian have made significant contributions to the standard of ethnographic writing and film expressions in terms of meaning construction (Jingjiang 2020).

The third path comes from cross-disciplinary cooperation. For example, the documentary A Year in Tibet (2009) by Sun Shuyun was jointly produced by China Tibetology Research Center and Beijing Horizon Culture Communication Co., Ltd., with Gelek from China Tibetology Research Center serving as the general producer. Through fruitful and professional cooperation and the effective field study, all the phenomena relating to Tibetan culture presented in this film are of important ethnographic value. Among the works produced by the teachers and students from the "Tsingying Film Studio" of Tsinghua University, most of them are targeted towards mass communication. However, the anthropological methodology and perspective persisting throughout the teaching and filming process have exemplified the possibilities of cross-disciplinary cooperation between anthropology and communication studies.

Moreover, as for the ethnographic films with "fictional" narratives, there are some acceptable "techniques of fictionality and performance" whose objective is to break through the sense of reality deeply rooted in previous ethnographies, thus to explore the possibility of experiencing the culture better (Jingjiang 2015). This is an experimental method of practical and academic value. At the very least, there would be fewer lies and illusions in "fictional" films than in "documentary" films, because the author and audience are both aware of the distance between imagination and reality. For example, The Winter Solstice in the Valley of the Golden Wing (2016) by anthropologist Zhuang Kongshao has been positioned somewhere between film documentation and drama performance. This film has provided an experimental text on the dramatic interpretation and visual presentation of local folktales. 


\section{Avant-Garde tradition and sensory ethnography}

In the realm of literature and art, the avant-garde tradition originated in the midnineteenth century. Its development was driven by the questioning and criticism towards the increasingly institutionalized modernism, and the linguistic turn in the fields of philosophy, art criticism, and the entire academic system afterwards. Influenced by the postmodernism trend, anthropologists, especially cultural anthropologists, began to reflect upon the discipline itself, and constantly questioned the etic superiority in scientism and positivism. The methods of meaning construction have been shifted towards the field of humanities: substantial terms such as ethnographic writing, reflexive ethnography, interpretive anthropology, emic and subject, discourse and text have entered the academic field (Ming'an 2009). Just as "objective" scientific research has been isolated from the subject of its knowledge and is constantly under question in terms of its context, the self-awareness and subjectivity of individuals have also been re-examined. An individual's thoughts and selfexpression usually take place during moments of "fragmentation," "pause," or "spontaneity," namely the moments for "poetic wisdom," when they interact with history and culture. At the same time, as the "common" wisdom, poetic rhetoric devices are also becoming a means of tracing the humanities and social sciences back to their source (Heng 2012).

As a presentation method with unique strengths in expressing poeticism, dreams, spontaneous moments, and synesthesia, the "avant-garde" attempts and practices in films have an even longer history. Due to the prevailing trends of futurism, Dadaism, and surrealism in the field literature, painting, and drama, modernist photography emerged in the early twentieth century. As a part of modern photography, modernist photography keeps a deliberate distance from practicality and does not take films as a tool of mass communication. It is more like a groundbreaking expression of ideas and visual experiment, and has been regarded as the "avant-garde," which embodies the attempts to use images to explore more possibilities in the visual world and promote profound changes in people's minds (Wenfang 2003). In the 1920s, as more and more professionals entered the film industry, the development of "avant-garde" films had gradually transitioned from the stage of France-centered impressionism (before 1925) to surrealism (after 1925). After 1927, the "avant-garde" filmmakers began to shift their focus to the presentation of real life, leading to the "third avant-garde school" which was dominated by documentaries. It is widely recognized that Berlin: Symphony of a Metropolis is an "avant-garde" documentary which relies on rhythms, video fragments, and polysemous expressions in the real sense (Wen and Lan 2010). During the filmmaking process which aims to create poetic images from daily lives, filmmakers have been fully committed to using different montage techniques to "make a good coat out of poor cloth". After watching those visually striking films, the audience come to realize that what matters the most is not the forms and flashy techniques, but the filmmakers' ideas hidden behind them (Huimin 2014). From then on, Dziga Vertov, Joris Ivens, and Godfrey Reggio have made many experiments: the narrative structure was deliberately neglected; efforts were redoubled in exploring the possibilities of montage techniques; and substantial metaphors and 
symbolic devices have been used. In doing so, the "avant-garde" films have been carried forward in a textual form which is extremely subjective, forming a "poetic" tradition. In the production practices of modern documentaries, "avant-garde" films which were once a niche for elites have become the medium of mass communication, as in documentaries themed on humanities by Jacques Perrin and Ron Fricke.

The experiments of films and anthropological texts stem from different traditions; yet, they may be attributed to the overall context and cultural trends of reflection on how best to present the real world. As a result, aside from films, ethnographic texts have also received great influence from poetic trends, and laid a solid foundation for the revolution of ethnographic films through the concept of reflexive anthropology. From a postmodernist perspective, ethnographies should either be poems or allegories. Postmodernist ethnographies are poems - in terms of the original contexts and functions rather than the forms. Using completely different methods of expression from those used in daily life, quasi-allegorical ethnographic works have aroused the memory of national spirit (or ethos) and thus animated their audiences. Postmodernist ethnographies have been striving to recreate the spiral presentation process of poetry and rituals through texts. These boast the meaning of visual expression and religious allegory, although there are no fixed narrative forms (Taylor 2006).

Since anthropologists stopped claiming that ethnographic writing belonged exclusively to anthropology, ethnographic films have entered a bigger genealogy of film expression, which contains shared film contexts and continues to influence media practices. In fact, many expository documentaries, non-fiction films, and news programs focus on just a small range of topics, and often interpret the world by "talking heads", which can hardly be experienced by the audience. Nevertheless, narrative films are usually confined to specific individuals and events, tending for the most part to "see the big picture through trivial events". They cannot do better than ethnographic texts in terms of navigating the macro perspective, social scenarios, and specific events.

In the view of another school of anthropological filmmakers, films are particularly significant because they manage to create a subjective individual experience, and have the ability to experience an entire abstract culture through visual anthropology (Castaing-Taylor 2008). Therefore, the poetic tradition has once again seen an upsurge, and batches of experiments in the field of visual anthropology have been carried out on this topic recently. The Sensory Ethnography Lab of Harvard University focuses on filmmaking that combines sensory aesthetics with ethnography. With the help of "sensory ethnography", the Lab aims to figure out how to convey anthropological thoughts, criticisms, and concerns towards the mainstream world through "non-mainstream" audio-visual experiments. However, such concerns have escaped the expository and narrative traditions of clue construction. No matter which film shooting technique has been used, be it a super long shot as in People's Park (2012) by J.P. Sniadecki or the juggling montage in Leviathan (2012) by Lucien CastaingTaylor, the filmmakers still want to follow the "avant-garde" context - stay critical of their own culture and society, challenge the traditional methods of narration and artistic expression, emphasize returning to the film itself, commit to the holistic and impressionist presentation of culture, and ensure that the film be experienced by the audience with more sensory dimensions involved. 
Films of this kind boast comparatively higher subjectivity and experimentality. In China, they are usually closely related to contemporary art, rather than anthropological studies. For example, in the experimental documentary film San Yuan Li (2003) by Ou Ning and Cao Fei, the directors used a large number trivial shots to restore the mixed reality of San Yuan Li, a famous urban village in Guangzhou, and the metaphors behind those changes. In Disorder (2009), director Huang Weikai collected materials taken by digital video enthusiasts to construct an urban symphony full of black humor. Most of these works pay tribute to Dziga Vertov, and inherit the structural and lingual traditions of "avant-garde" films. In addition, since video production has gradually become part of the Chinese people's daily lives, automatic video capture devices such as surveillance cameras and user-produced content such as smartphone videos have become a reality. The relationship between the mediatized reality and visualized bodies has been keenly explored in some film experiments. The artist Xu Bing produced a full-length feature film Dragonfly Eyes (2018) with real recordings captured by surveillance cameras across the city, in which all the plots and characters were fictional. In collaboration with the videosharing platform Kuaishou, "Tsingying Film Studio" screened and reorganized hundreds of thousands of short videos. Through five split-screen film experiments, the studio produced a cinematic documentary film full of spectacle and emotion This is Life (2020). By making great innovations in film language, this film is a direct response to the era of nationwide video production in China. Nevertheless, these works are usually faced with the same challenges as Leviathan - they are not viewed as classic ethnographic films, but documentary films or experimental ethnographic films from the perspective of sensory anthropology. Thus, these works are quite marginal within anthropological knowledge production.

\section{Reflexive tradition and reflexive ethnography}

Films, which can be directly perceived by the audience, are quite different from texts in terms of their capacity for self-representation. In 1839, Hippolyte Bayard and Louis-Jacques-Mandé Daguerre competed to file a patent for the photographic process. However, Bayard failed. As a response to this injustice, Bayard created Self Portrait as a Drowned Man, which happened to be the first ever "selfie" and body language film in the world. Throughout the history of the film industry, realistic contexts featuring the objective and faithful reproduction of people's daily lives have been a presentational approach taken in film practice, as well as a theoretic school of film criticism. However, criticism of realism has always existed, and the most important concept is "reflexivity". Through the continuous examination of the filmmaking process in terms of space and time - both in reality and in the film - the identity of makers, and the role of cameras, these critics aim to question the "realistic" nature of meaning construction and the fixed mindset of the audience who have accepted these films (Yanming and Wencong 2011). In this process, many filmmakers and documentary makers have been dedicated to tackling the awkward or puzzling situation of "hidden cameras". For example, Shirōyasu Suzuki, Imamura Shōhei, and Kazuo Hara have made several attempts to produce "first-person documentaries"; Nick Broomfield, Agnès Varda, Morgan Spurlock, 
and Louie Psihoyos have also produced many documentaries from the first-person point of view, including Driving Me Crazy (1988), Les Glaneurs et La Glaneuse (2000), Super Size Me (2004), and The Cove (2009). Other renowned classic documentaries include Man with a Movie Camera and Chronicle of a Summer (1961), as well as some works produced in China such as Treatment (2010) by Wu Wenguang and Using (2007) by Zhou Hao.

Interestingly, in the second half of the twentieth century, the field of natural sciences began to see changes in how scientists explored objective laws. The experimental results of Bell's inequality in the 1960s supported the uncertainty principle followed by the Copenhagen School. This shook the cognitive foundations of science, which at the time were purely objective. Quine and Kuhn's post-empiricist outlook on the philosophy of science negated the value of positivism and the outlook on research with neutral theory. Afterwards, the emergence of hermeneutics laid a solid foundation for the end of Descartes' era of scientism (Yunxing 2007). Following basically the same timeline from the 1960 s to the 1980 s, phenomenology, hermeneutics, and postmodernism began to escape from the knowledge production paradigm of scientism. Paul Rabinow challenged objectivity and regularity through his work Reflections on Fieldwork in Morocco; and Vincent Crapanzano's Tuhami: Portrait of a Moroccan and Kevin Dwyer's Moroccan Dialogues: Anthropology in Question contributed to the development of reflexive ethnography (Bingzhong 2006).

If "avant-garde" films mark the first attempt to break the established structure from the hierarchy of visual presentation, postmodernist ethnographies focus on another aspect - why and how anthropology can help people recognize the object world. In the field of communication, "avant-garde" films impose challenges on overly structured films from the perspective of the film itself and intuition, with more attention paid to the subjectivity of filmmakers and the ontological legitimacy of visual texts. If taking a step further, these films may discuss the possibilities of synesthesia between the audience and communicators at a sensory level. However, postmodernist ethnographies impose challenges on texts from the perspective of the text itself and the logic. It is believed that discourses are superior to texts, and texts are merely a form of monologue. Researchers' objective observation of objects is no more than a form of stories or dialogues - ethnography is a dialogue by nature (Yunxing 2007). The transition from "truth" to "dialogue" unveils the holistic understanding of knowledge production and knowledge communication in the human society. Therefore, across the entire chain of ethnographic studies (namely, the object world - observer - communicator - audience), various kinds of powers, relationships, and credibility can each be revealed and questioned.

In fact, endeavors in the field of postmodernist ethnography have gone some lengths to solve an embarrassing problem faced by ethnographic films: since everyone knows that the "realistic" nature of objective, authentic, and scientific ethnography is questionable, ethnographic films may be no more "unreal" than ethnographic texts. On the other hand, films used to be regarded as performance and emotional thing attached to the objective reality; or, as I have heard on many occasions, a lot of anthropologists think "ethnographic films have done a great job in promoting anthropology." Films are often marginalized in the field of research, 
because they are "overly superficial" or "not abstract enough". However, films began to be viewed with importance due to the debates that followed the representation crisis (Jingjiang 2011).

As manifested by Jean Rouch and Joshua Lincoln Oppenheimer through their ethnographic works, ethnographic films which follow the reflexive tradition are naturally reflective and critical. The filmmaking practice proceeds in two approaches as follows. On the one hand, it challenges the mysterious God's perspective by emphasizing the process and describes the construction of meaning in the film openly. In other words, the filmmaking process and viewing process have been used as the filming object, thus to describe the engagement during the formation of the ethnography in specific scenarios, i.e., the empowerment and the sharing of anthropology advocated by Rouch. This has reminded ethnographic filmmakers that communication between the cameraman and the subject should not be avoided. For example, Hao Yuejun deliberately showed up in his documentary A Village in the Cave (1996). Moreover, the reflexive ethnographic film has urged filmmakers to put aside their own opinions and hear the voices of the object world. For example, Hu Taili invited some characters in the film The Voices of Orchid Island (1993) to discuss the shooting plan and their expectations. On the other hand, such filmmaking highlights reflexivity - in other words, encourages the legitimate self-representation of film objects. In the films, even fieldstudy objects have various opportunities to present or determine their own world. In this way, we can eliminate the shortcomings of scientist ethnographies that arise from seemingly scientific discourses. Sometimes, the established boundaries between reality and fictionality may be further expanded through improvisation and performance. For instance, as Xiong Xun includes in The Last Lineage Opera in Zhouguan Village (2017, RAI Film Festival) how he was "taken advantage of" by the villagers to perform the last traditional Dixi opera, thus completing the process of self-worth building.

The third form is the internal perspective of the holders of one culture, which is highlighted through the rapidly developing "community films" led by institutions with an anthropological background in the residential areas of ethnic minorities of Yunnan, Qinghai, and Guangxi. Among them, local film institutions and organizations such as Yunnan FROM OUR EYES Rural Documentary and Culture Research Center have played a significant role in promoting these films. For example, Lanze, a herdsman from Golog Tibetan Autonomous Prefecture of Qinghai Province created a documentary Yak Dungs in 2010. This film has presented how Tibetan people make full use of yak dungs and has interpreted the meaning of the local culture. Another peasant called Sonam Nyima from Diqing prefecture of Yunnan Province created Caterpillar Fungus in 2012. To find Caterpillar Fungus, villagers have to constantly climb truly enormous mountains (Jingjiang 2020). The documentary filmmaker Wu Wenguang launched a Villagers' Digital Video Project in 2005, which has enabled villager filmmakers to shoot and edit their own films in their home villages. As of today, some villagers are still working on their films. These works are not complete ethnographic films in the academic and theoretical sense, and some filmmakers have chosen to use an external point of view as well. Still, they play an indispensable role in presenting interwoven local knowledge and interpreting the evolution of cultural meaning. 


\section{Conclusion}

Among ethnographic films with an expository tradition, the approach to constructing meaning stems from modern ethnography's tendency towards scientism and the modernist context of visual communication. On the one hand, it is showcased through the dominant role of communicators rather than the audience; on the other hand, it is restricted by the logic of writing. Among ethnographic films with a narrative tradition, the approach to meaning construction can be identified through the interwoven audience-centered communication perspective and the classic narrative structure. The narrative tradition in films originates from industrial production and mass communication. Making full use of the strengths of audio-visual elements, narrative films have become an important audio-visual medium with a strong capacity for cross-cultural communication, giving birth to a set of effective and highly simplified film presentation structures. Anthropological filmmakers have proactively emphasized, or have been forced to realize the significance of films' narrative capacity in the field of communication. However, these works have been criticized by many ethnographic writers because they are not abstract, realistic, or meaningful enough. Therefore, they have been marginalized both in the fields of mass film communication and academic production. Deeply rooted in deconstruction, the "avant-garde" tradition is quite similar to those "avant-garde" experiments in painting, photography, and film. Ethnographic films may seem to have nothing to do with this tradition; however, they are closely related to each other in terms of the methods of expression and the origins of their concepts. Therefore, the "avantgarde" tradition may be a promising direction for the future development of ethnographic films. As for the reflexive tradition, it has always featured the context of dialogue between ethnographic practice and anthropological theory. However, its main objective is to arouse reflection upon the entire process of knowledge production and communication, and to present and criticize the social interaction in every part from a broader perspective. The approach to meaning construction in this tradition has helped communicators shake off their self-imposed shackles and facilitated exploration in all fields across the communication process.

Acknowledgements Not applicable.

Authors' contributions Xun Xiong conducts the research and writing. Jing Li is a major contributor in writing and research plan. All authors read and approved the final manuscript.

Funding This phasic work was supported by Guangdong Province Innovative College Talent Program (Project Name: "Cross-disciplinary Studies on the Community Relations and Cultural Communication in Online Video Communities"; Project No. 2018WQNCX279) and Fundamental Research Funds for the Central Universities (Project Name: "Film Production in Media Transformation: Studies on Ethnography Based on the Shift to "All-Media"; Project No. 14wkpy04).

Availability of data and materials Not applicable.

\section{Declarations}

Ethics approval and consent to participate Not applicable. 
Consent for publication Not applicable.

Competing interests We have no competing interests.

Open Access This article is licensed under a Creative Commons Attribution 4.0 International License, which permits use, sharing, adaptation, distribution and reproduction in any medium or format, as long as you give appropriate credit to the original author(s) and the source, provide a link to the Creative Commons licence, and indicate if changes were made. The images or other third party material in this article are included in the article's Creative Commons licence, unless indicated otherwise in a credit line to the material. If material is not included in the article's Creative Commons licence and your intended use is not permitted by statutory regulation or exceeds the permitted use, you will need to obtain permission directly from the copyright holder. To view a copy of this licence, visit http:// creativecommons.org/licenses/by/4.0/.

\section{References}

Bazin, André, translated by Cui Junyan (崔君衍译), What is Cinema?(《电影是什么?》), Beijing: Culture and Art Publishing House (北京:文化艺术出版社), 2008. P10 (第10页).

Bill Nichols, Introduction of Documentary, trans. by Chen Xihe (陈犀禾), Liu Yuqing (刘宇清) and Zhen Jie (郑洁), Beijing: China Film Press (北京:中国电影出版社), 2007. P114 (第114页).

Bingzhong, Gao (高丙中), The three periods in the development of ethnography--Translator's preface to writing culture (《民族志发展的三个时代》), Naning: Journal of Guangxi University For Nationalities (南宁:广西民族学院学报), 3, 2006. P58-P63 (2006年第3期, 第58-63页).

Castaing-Taylor, Lucien (2008) at From Vérité to Virtual: Conversations on the Frontier of Film and Anthropology, http://search.alexanderstreet.com/view/work/764224. Accessed 8 Mar 2016.

Giannetti, Louis (2007), translated by Peggy Chiao (焦雄屏译), Understanding movies 11th ed (《认识电 影(第11版)》), Beijing: World Book Inc (北京:世界图书出版公司), 2007. P211 (第211页).

Henley, Paul, translated and edited by Zhuang Zhuang, Xu Han (庄庄, 徐菡编译), Narratives - the guilty secret of ethnographic documentary? (《叙事: 民族志纪录片深藏的秘密?》), Kunming: Thinking (昆明: 思想战线), 2, 2013, P34-P41 (2013年第2期, 第34-41页).

Liu Heng (刘街), Poeticism of ethnography: On the theories and practices of anthropology for the dimensions of “self” (《民族志诗性: 论“自我”维度的人类学理论实践》), Beijing: Ethno-National Studies (北 京:民族研究), 4, 2012. P37-P48 (2012年第4期, 第37-48页).

Li Wenfang (李文方著), The world history of photography (《世界摄影史》), Ha Erbin: Heilongjiang People's Publishing House (哈尔滨:黑龙江人民出版社), 2003, P243 (2003年, 第243页).

Pang Huimin (庞慧敏), Creation characteristics of German Avant-Garde documentaries (《德国先锋纪录片 的创作特征》), Beijing: China Television: (Documentary) (北京:中国电视(纪录), 1, 2014. P23-P25 (2014年第1期, 第23-25页).

Qu Ming'an (睢明安), Review on Western postmodernist anthropology (西方后现代主义人类学评述), Beijing:Ethno-National Studies(北京:民族研究), 1, 2009. P31-P40 (2009年第1期, 第31-40页).

Taylor, Stephen A., Postmodernist ethnography: From records of mysterious things to mysterious records, collected in Writing culture: The poetics and politics of ethnography (《后现代民族志: 从关于神秘事物 的记录到神秘的记录》, 收录于《写文化:民族志的诗学与政治学》), [US] edited by James, Clifford, George E. Marcus ([美] James Clifford、George E. Marcus 编); translated by Gao Bingzhong, Wu Xiaoli, Li Xia etc.(高丙中、吴晓黎、李霞 等译 ), P163-P181 (第163-181页), Beijing: The Commercial Press (北京:商务印书馆), 2006 (2006年6月).

Yunxing, Ruan (阮云星), On ethnography and methodologies of social sciences (《民族志与社会科学方法 论》), Hangzhou: Zhejiang Social Sciences (杭州:浙江社会科学), 2, 2007. P25-P34 (2007年第2期, 第 25-34页).

Zhu Jingjiang (朱靖江): Crisis of anthropological presentation and “deep description” of ethnographic films (《人类学表述危机与“深描式” 影像民族志》), Wuhan: Journal of South-Central University for Nationalities (武汉:中南民族大学学报), 6, 2011. P28-P32 (2011年第6期, 第28-32页).

Zhu Jingjiang (朱靖江著), Enlightenment in the field - Diachronic investigation and theoretical research of ethnographic films (《田野灵光一人类学影像的历时性考察与理论研究》), Beijing: Xueyuan Publishing House (北京:学苑出版社), 2014. P153-P157 (2014年, 第153-157页). 
Zhu Jingjiang (朱靖江), Fictional ethnographic films: Visualization of the internal world (《虚构式影像民族 志: 内在世界的视觉化》), Kunming: Journal of Yunnan Nationalities University (昆明:云南民族大学 学报), 1, 2015. P43-P47(2015年第1期, 第43-47页).

Zhu Jingjiang (朱靖江): Cultural presentation and new wave of films: Experiences and reflections on Chinese ethnographic documentaries over the past decade (《文化表达与影像新潮: 中国民族志纪录片十年 经验及反思》), Kun Ming: Ethnic Art Studies (昆明:民族艺术研究), 6, 2020. P60-P68 (2020年第6期, 第60-68页).

Zhou Ting (周霆): Ethnographic Narratives: A Literary Ethnographic Perspective (《民族志叙事:一个文学 人类学的视角》), Hei Longjiang: Youth Literator (黑龙江:青年文学家), 23, 2015. P14-P16 (2015年第 23期, 第14-16页).

Zhou Wen, Zhou Lan (周文、周兰), Exploration and analysis of Avant-Garde documentaries (《先锋纪录片 探析》), Beijing: Modern Communication (北京:现代传播), P100-P104, 2010. (2010年第1期, 第100104页).

Zhao Yanming, Li Wencong (赵艳明、李文聪), Debunking the Myth of Realism - On the Realistic and Reflexive Nature of Films (《打破写实的神话一论电影的现实性与反身性》), Ha Erbing: Literature and Art Criticism (哈尔滨:文艺评论), 5, 2011. P123-P128 (2011年第5期, 第123-128页)

\section{Comments}

Publisher's Note Springer Nature remains neutral with regard to jurisdictional claims in published maps and institutional affiliations. 